This article has been accepted for publication and is forthcoming with Screen (vol. 58:1, Spring 2017).

\title{
Love Sex Aur Dhoka: A New Morphology of Contemporary Bombay Cinema ${ }^{1}$ Anuja Jain, University of St Andrews, UK
}

The economic liberalization of the 1990s affected two pertinent shifts within the socio-material life of the Indian nation-state - a rapid media expansion, and the rise of a new middle class identity. Informing these shifts was a volatile interface of politics, technology and the market. Congruent with the processes of economic liberalization has been the emergence of a new cinematic order, one that is variably designated as 'multiplex cinema,' 'new Bollywood' or 'Hatke cinema.' As opposed to the traditional single screen theatre, this contemporary new cinema is informed by inventive story telling conventions, aesthetic forms and departures from dominant dramaturgical modes ${ }^{2}$.

Catering to a niche, but committed, urban middle-class audience this new cinema was part of the post liberalization urbanscape marked by the visceral presence of technology. Following the fervent urbanisation that started in the late 1980s and accelerated with the economic and financial reforms of the 1990s, Indian public culture by the 2000s had witnessed an unending flow of commodities, new techniques of reproduction and a deliriously expanding media ecology.. The following decade witnessed a landscape where human existence came to be embodied and articulated by mediations with a lasting impact on society and human interaction. A new 'metropolitan diagram' emerged that aggressively recast the urban as 'a site for news, surveillance, security, advertising, entertainment, consumer choice, products, marketing, spying [...]'.3

\footnotetext{
${ }^{1}$ I would like to thank Sudhir Mahadevan for his invaluable comments and suggestions on the essay.

${ }^{2}$ Since the mid 2000s, in conjunction with the shift from a Nehruvian developmentalist paradigm to a neoliberal context, the Bombay film industry witnessed a dramatic corporatization and regulation of the production and finance practices. The re-organization of industrial practices not only drastically altered modes of movie distribution and exhibition, engendering structural transformations of the Bombay film industry from a highly unregulated unorganized sector located within the domain of India's informal economy to its refashioning as a global entertainment industry, but also made viable experimentation and new transformations in film form and style, seminally within the purview of commercial cinema. For a detailed discussion of the transformations in the Bombay film industry's production culture and filmmaking ideologies during the period of tremendous social and economic change in India See, Tejaswani

Ganti, Producing Bollywood: Inside the Contemporary Hindi Film Industry (Durham: Duke University Press, 2012).

${ }^{3}$ Anustup Basu, Bollywood in the Age of New Media: The Geo-televisual Aesthetic (Edinburgh: Edinburgh University Press, 2010), p. 97.
} 
One came to inhabit a new 'media urbanism'4 - an urban sensorium of legal, non-legal spheres and technological infrastructures composed of reality TV, 24 hour electronic media flows, YouTube, smartphones, surveillance equipment, space technology and nuclear militarization. Enabled by new principles of automation, and variability, ways of accessing, inhabiting and consuming this new mediascape completely changed for its inhabitants, and so did the very nature and forms of pleasure.

Situated within these transformative interfaces, this article analyses Dibakar Banerjee's Love Sex Aur Dhoka/Love Sex And Betrayal (2010). While the new cinema that emerged in congruence with the processes of economic liberalization is characterised by a stunning multiplicity of genres and styles, departing from the homogeneity enforced by the idioms of the social or the masala film to innovatively experiment with cinematic form and structure, Love Sex Aur Dhoka stands out as a distinctive cinematic text. The film's found footage style, cinematography, unknown actors, and episodic non-linear narrative is hardly typical of the the terrain traversed by mainstream Indian cinema. The film is entirely digital and composed of three seemingly untied stories that allude to the 'Love', 'Sex' and 'Dhoka' or betrayal in the title respectively.

This article explains how the film is symptomatic of new and present media ecologies as well as being indicative of a potent moment in the post Bollywood history of Bombay cinema. It is the new form of technologically embellished urbanism, marked by experiences such as sting operations, sex scandals, and home videos that is the subject of Love Sex Aur Dhoka. It is an interrogation of a world that, as noted by the film's official website, 'attaches a premium to making personal life public, deliberately, accidentally or unintentionally'. ${ }^{5}$ Along with a deliberation on the invasive culture of the hyper-visual, the film is also a conscious deliberation on the materiality of cinema, its poetics and form especially in the present moment when there has been a profuse diffusion of filming and recording apparatus in everyday life and social relationships. Significantly, long before its release, the film's official website hosted multiple videos of Banerjee and his cinematographer Nikos Andritsakis talking about the conceptualization and making of

\footnotetext{
${ }^{4}$ Ravi Sundaram, Pirate Modernity: Delhi's media urbanism (New York: Routledge, 2009).

${ }^{5}$ Website no more available. Accessed in May 2011 for a version of this paper presented at the international conference, 'What's New? The Changing Face of Indian Cinema: Contemporary and Historical Contexts,' University of Westminster, UK, 8-9 July 2011.
} 
Love Sex Aur Dhoka. In these 'tutorials' Banerjee and Andritsakis deliberate at length on the aesthetics and politics of the film, addressing questions about the digital format of the film, the new cinematic idiom of looking at the moving image in contemporary times saturated with the technologies of image reproduction. ${ }^{6}$

This article moves away from a discussion of the film's adoption of digital technology and aesthetics in service of notions of truth, access and celluloid ${ }^{7}$ that exemplify the 'union of the conjugal form and film aesthetics' characteristic of the 'New Bollywood. ${ }^{8}$ Instead, it deliberates on the way Love Sex Aur Dhoka reflects critically on the restructuring of the relationship between the camera and human subjectivity by playing with different generic strains and expectations within the segments, rendering the film internally heterogeneous. I argue that the use of generic codes and aesthetics, from the intimacy of the home video to the ambivalence of the suspense thriller, allows the film to foreground its own constructed-ness. Rather than attempting to collapse the distinction between the 'real' and the 'image,' it reflects on the relationship of the image to the apparatus of its reproduction. I show how the film elucidates new forms of engaging with the materiality of the present and emergent world order, and how it explores the intimate, visceral engagement between the film's and viewer's bodies in the contemporary hyper mediatized landscape, constituted by and constitutive of new Bombay cinema.

\section{Film Bodies, Genre and Technology}

Set in a film school, the first segment titled, 'Superhit Pyaar' (Superhit Love) is the story of Rahul, a lower class film student working on his diploma film; Shruti, an upper middle class girl who comes to audition for his film and ends up becoming his love interest; and Aditya Chopra, the famed Bollywood film director who 'inspires' Rahul and

\footnotetext{
${ }^{6}$ The official website is no more available. It was accessed in May 2011. The videos can be seen on YouTube, < https://www.youtube.com/watch?v=BNzxltaoKYs> [accessed 28 July, 2015]. For a more detailed discussion of the discourse around the making of LSD, official and otherwise, see Kuhu Tanvir, "Through the digital peephole: LSD and the grammar of transparency, "South Asian Popular Culture, vol. 13 , no. 1 (2015), pp. $1-15$

${ }^{7}$ Tanvir, 'Through the digital peephole.'

${ }^{8}$ Sangita Gopal, Conjugations: Marriage and Form in new Bollywood cinema (Chicago, Chicago University Press, 2011), p. 187
} 
is his 'reel life' love interest. ${ }^{9}$ In his student film Rahul aspires to pay homage to his favorite movie, the 1990s blockbuster Dilwale Dulhaniya Le Jayenge/The Brave Hearted Will Take Away the Bride. ${ }^{10} \mathrm{He}$ tries to impersonate Raj, the male protagonist from Dilwale Dulhaniya Le Jayenge, and the entire segment of the film is shot on Rahul's handy cam as a video diary (Image 25-27).

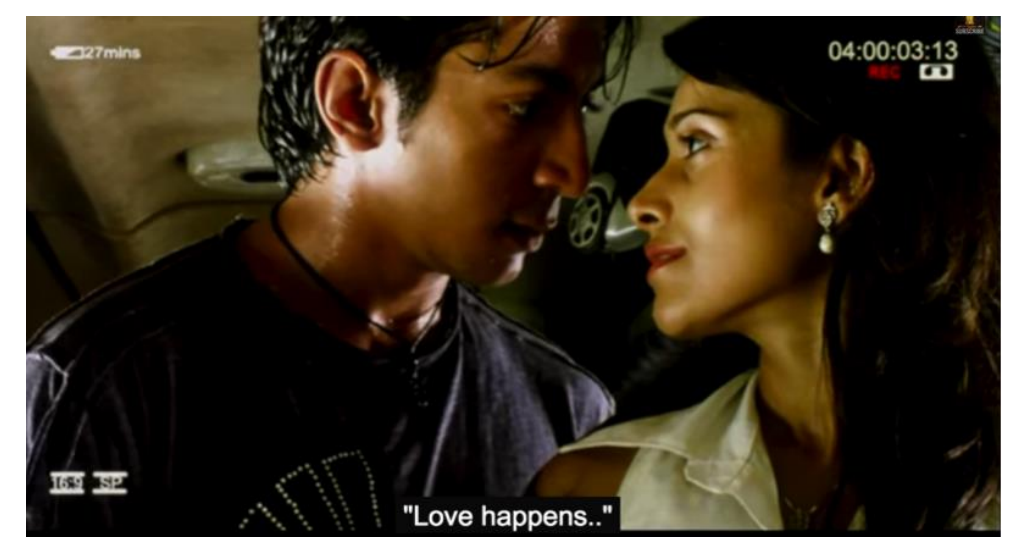

25.

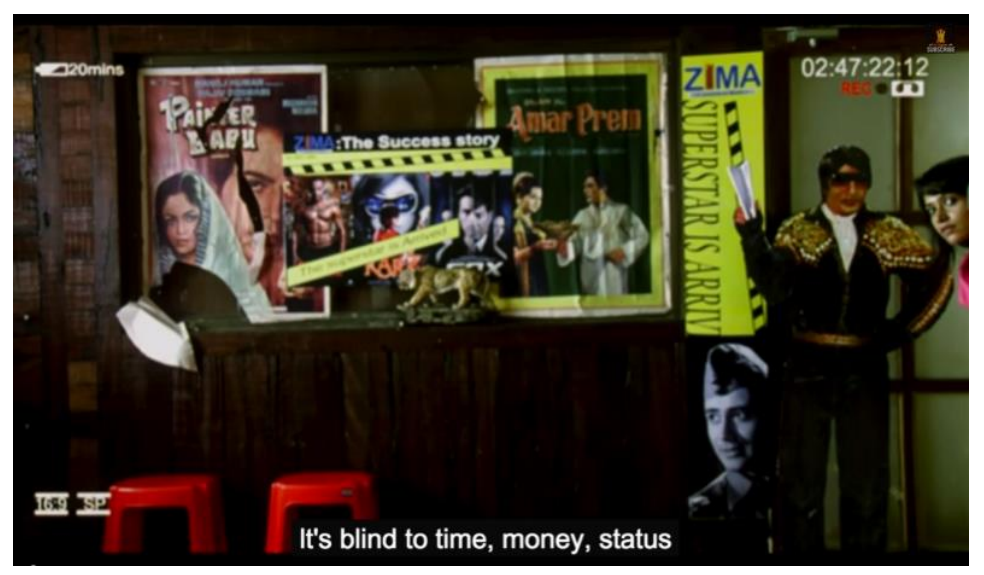

26.

\footnotetext{
${ }^{9}$ Aditya Chopra is an Indian film director, producer, screenwriter and distributor, and son of famed Indian film director-producer Yash Chopra. He is also the current chairman of the multi-national film, media and entertainment conglomerate, Yash Raj Films (YRF) and has written and produced a number of critically acclaimed and commercially successful films under the banner, including DDLJ which is one of biggest blockbuster films of later half of the twentieth century.

${ }^{10}$ Directed by Rahul's muse, Aditya Chopra it was a seminal film of the 1990s that ushered in an era of big budgeted family films within the Indian film industry, marking the emergence of 'Bollywood,' a form of filmmaking that largely caters to the Indian diaspora. See, Ashish Rajadhyaksha's "The 'Bollywoodization' of the Indian cinema: cultural nationalism in a global arena" in Inter-Asia Cultural Studies, vol. 4, no.1 (2003), pp. 25-39.
} 




27.

Drawing on home movie aesthetics, this segment invokes the randomness, ordinariness and intimacy associated with the genre through a collage of fragments from Rahul's life. By foregrounding a found footage style, Banerjee recycles images and memories from Rahul's 'private archives of memory'. ${ }^{11}$ Rather than invoking nostalgia for the old analogue form, the segment draws on the generic strains of home movies to critically reflect on the relationship between Rahul and his camcorder. As Fred Camper notes, while home movies are extremely various in their manifestations, one of the distinctive feature of a home movie is the way in which 'home movies are filmed, the particular relationships established between the camera (representing implied filmmaker/family member) and the subject-matter [...]'. ${ }^{12} \mathrm{He}$ also points out that given the brevity of the home movie roll, the selection and the 'highlights' that often inform such recordings are telling of what the maker of the home video finds worthy of preservation. In the instance of this segment, as the home video aesthetics intensifies the authenticity of the text, together with the 'highlights' one witnesses how Rahul's relationship with his camcorder and the addressee of most of his recordings, Aditya Chopra, comes to be marked by a fetishisation of such technologies and practices.

Many media scholars have argued that the mixing of technology and urban life has been an enabling moment for subaltern populations with the low cost technologies of mechanical and digital reproduction blurring the distinctions between the producers and

\footnotetext{
${ }^{11}$ Ayisha Abraham, "Deteriorating Memories: Blurring Fact and Fiction in Home Movies in India," Mining the Home Movie, ed. Karen Ishizuka and Patricia Zimmermann (Berkeley: University of California Press, 2007), pp. 168

${ }^{12}$ Ibid., p. 10
} 
consumers of media and making it possible for the material existence of such 'informal' networks, like the home video or the student film in this instance, without being incorporated by the state or large capital. ${ }^{13}$ I would argue that for Rahul it is the very act of recording and playing with his camcorder that is the primary pleasure. The direct address to the camera functions as a source of access for him - access to possibilities, both reel and real that are otherwise unavailable to someone like him who comes belongs to a lower caste and comes from a non-film background. However, while this easy access to technology enables a student with no connections or monetary resources to make a film, the system of casteism and honour killings ${ }^{14}$ that still permeate urban Indian modernity, bar the materialization of either his diploma film or his love story outside the film.

In a pivotal sequence, Rahul and Shruti reveal to Shruti's family that they have eloped and got married. Following prompt acceptance by the family, Rahul immediately (and obviously) wants to share the jubilant moment with his avowed mentor Aditya Chopra, whose cinema is quintessentially marked by happy resolutions and the reinstating of the family structure. Mid way, as Rahul turns the camera towards Shruti, cajoling her to also say something, the recording abruptly cuts to both of them in a car on their way to meet Shruti's parents. Rahul worries that he has probably pressed the wrong button on the camcorder and some old footage might get deleted. Following their interception by Shruti's brother and a brutal killing, the recording of their jubilant and gratuitous messages to Aditya Chopra once again abruptly resumes with Shruti thanking her family for accepting them. As the jarring accidental jump cuts and non-continuity editing accentuates the fate of such alliances, the resumption of the interrupted footage by the narration after they are dead significantly reveals the home movie's powerful persistence as an intimate record of the body even after it is deceased. It underscores what Fred Camper points to be the 'dominance of the images we create of ourselves over our

\footnotetext{
${ }^{13}$ Sundaram, Pirate Modernity, p. 3-4.

${ }^{14}$ Honour killings are a real phenomenon in contemporary India - it refers to a practice of male family members killing a female relative to protect what they perceive the honor of the family. It is most common among middle-to upper middle class, semi-urban families.
} 
actual bodies', as the instantaneous availability of these images on home video, as opposed to the film, allows them to become a part of our lives in real-time. ${ }^{15}$

This sequence also invokes the technical 'inadequacies' of home movies, and draws attention to the technologies of reproduction, its fallibility and multiple pleasures. Camper observes that ' $(\mathrm{t})$ he many technical "inadequacies" of most home movies, such as shaky camera, jumpy editing, and varied and discordant lighting effects, all must be seen as distancing it from the realm of the commercial feature, even in many of those cases in which the filmmaker is trying to imitate [the] same.' 16 Through the dual register of the 'technical inadequacies' as described by Camper, along with the parodic filmwithin-film where in his student film Rahul attempts an amateur remaking of Dilwale Dulhaniya Le Jayenge, Banerjee underscores the critical distance from Bollywood cinema. Instead, the segment self reflexively offers a critique of the 'Bollywoodisation' of Indian cinema that is composed of the melodramatic tropes of romance and family which are often mobilized to project a dream world, a hypermodern landscape of excess and a shining 'new' India.

As the segment invokes the pleasure involved in watching home movies as found footage, it also makes us aware of how the status of the original footage changes for the viewer when presented as part of a film. Home movies often invite us to use a process of remembering that builds towards celebration. However, in this instance rather than invoking an euphoric experience, we witness the tragic and cruel end of Rahul, Shruti and Aditya Chopra's love story. The ending with its out of focus, scratched images demands that we, as spectators, produce the images and transform the stillness of the footage into movement. With several minutes of hard-to discern-images and disorienting on-location sounds, the fragment serves as a moment of torture for the spectator, operating simultaneously with the story of Rahul and Shruti's torture.

The second segment titled, 'Paap Ki Dukaan' (Shop of Sin) further explores this intimate and tactile contact between the apparatus and the viewer's bodies. It is the story of Adarsh, a security camera agency executive; Rashmi, the plain 'dark' quiet middle

\footnotetext{
${ }^{15}$ Fred Camper, "Some Notes on the Home Movie," Journal of Film and Video, vol. 38, no. 3/4, (SummerFall 1986), pp. 13

${ }^{16}$ Camper, "Some Notes on the Home Movie," p.11
} 
class sales girl, and the four CCTV cameras in a small upcoming 24-hour department store franchise. Always looking for 'get rich quick' schemes, Adarsh is advised by his friend to seduce Rashmi and make a porn clip through the security cameras and sell it in the market for guaranteed high returns (Image 28-29). As the story progresses, we see the relationship between Adarsh and Rashmi becoming implicated in the complex urban web of of fragile male ego and a desire for social mobility.

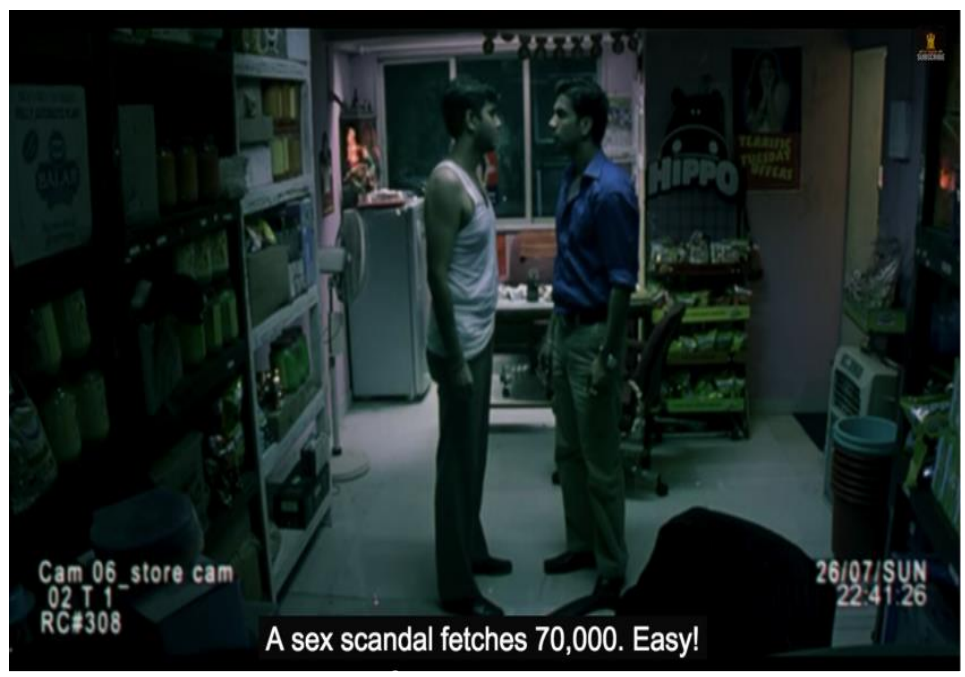

28.



29.

Narrated from the point of view of the store's CCTV cameras, one might argue that this story is another instance of the use of technology to control, discipline, identify and sort people, with the caricatured security guard of the departmental store being a reminder of the self-sufficient efficiency of the technology. The very surveillance that 
creates an illusion of comfort and security for the new middle class turns out to be predatory, violent and voyeuristic (Image 30). As Adarsh's friend reminds him, 'the camera is the key to a treasure,' Rashmi is reduced to a dis-embodied and circulated sexual image. With the making of the sex clip, we witness a de-coupling and sense of objectification taking place with human bodies being transformed into a non-linear web of libidinal pulsations and image flows that are rapidly dispersed for consumption.



30.

With the third and final story, 'Badnam Shohrat' (Disgraced Fame), the film further queries the implications of the ubiquitous and invasive presence of new technologies and practices. This story is about Naina who wants to be an 'item girl', but pop singer Loki Local is ready to give her a break only if she is willing to 'compromise.' Hurt and dejected, Naina decides to expose Loki with a sting operation with the help of a journalist Prabhat. The segment draws upon the genre of suspense thrillers with the use of the 'sting operation' demonstrating how such conventions and imagery have become naturalized codes that are neither arbitrary nor incoherent.

Through the vignette, Banerjee plays with audience expectations and foregrounds the use of the sting camera as a calculated device for invoking the paradoxical emotions of humour and suspense, fear and excitement. For instance, as we witness Prabhat training Naina to use the camera and prepping her to carry out the sting on Loki Local, their playful interaction creates a tension between identification and detachment. On the one hand, the use of intimate close ups and soft saturated colours draw us in to their flirtatious banter, but the fact we never actually see Naina during most of the sequence as 
she becomes the 'eye' behind the camera also creates a simultaneous sense of detachment.

The vignette addresses the very close merging of entertainment with invasive spying devices for spectacle and voyeuristic delight (Image 31). The exchange between Naina and Prabhat, where the camera cuts from medium close up to an extreme close up of Naina sitting seductively near his lap; the muting of sound over Loki Local and Naina's exchange in the coffee shop during the sting; and the aesthetics of poor framing and grainy compressed images, all invoke suspense and a sense of anticipation behind the sting operation.



31.

The story ends with Prabhat refusing to hand over the sting footage of Naina obliging Loki Local with sexual favors to save her dignity, and Naina betraying Prabhat by accepting to be an item girl in Loki Local's new music video. Notwithstanding Loki Local's music video, with its kitschiness featuring Naina in a parody of the 'sting operation' culture, the segment ultimately reminds us that this new media practice and its practitioners are very much embedded within a unsavory constellation of capitalism and voyeurism. We are far from what David Garcia and Geert Lovink identify as 'tactical media' - a media practice that is conceptualized on an 'aesthetic of poaching, reading, speaking $\ldots$ clever tricks, $[\ldots]$ maneuvers $[\ldots]$ joyful discoveries, poetic as well as 
warlike ${ }^{17}$ made possible by the revolution of consumer electronics and expanded forms of distribution. Rather than being the alternative media forms of 'crisis, criticism and opposition', ${ }^{18}$ sting operations expose the filming apparatus to be subject to corruption, and a source of chaos and terror.

\section{Affective Engagements and Embodied Spectatorship}

Implicated within the visual economy of watching and being watched - which is rendered familiar with ordinary middle class characters and everyday spaces, and hence even more fearful - Banerjee invites us to traverse this maze with the characters we 'know'. Nonetheless, the film makes us uneasy precisely because it refuses any easy identification between viewers and characters, and it does so by constantly drawing attention to the third body in the equation, that of the camera.

For instance, the first story, love, ends with the gruesome killing of Rahul and Shruti by Shruti's brother and his aides. What we witness on Rahul's handy cam, that is still switched on when they are intercepted, is the blinking of the recording sign, jerky motions, on location sounds of both the characters and the fall of the camera (Image 32 35). These reality effects lend the scene a haptic quality, establishing an intimate and tactile relation between the bodies of the characters, the viewer and the camera that continues throughout the film.

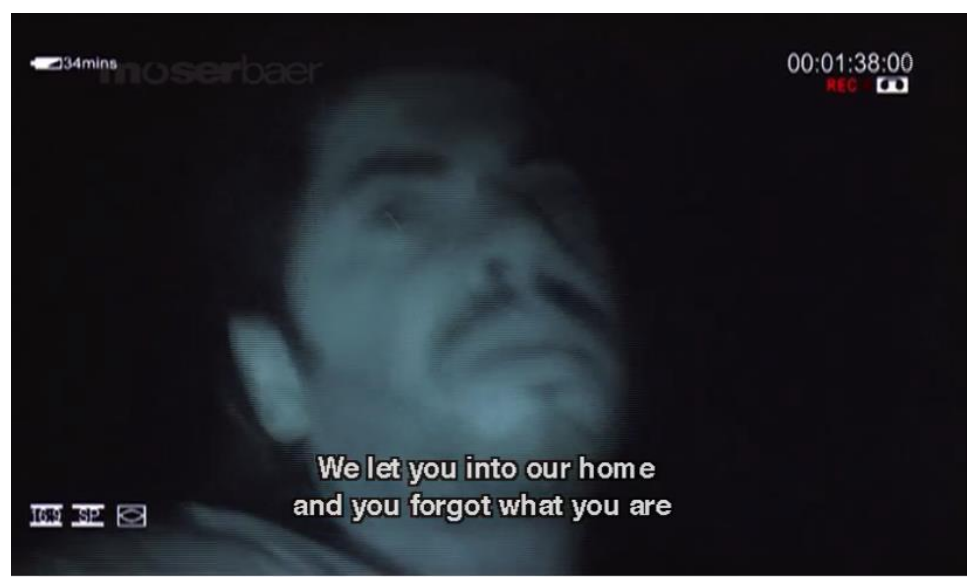

32.

\footnotetext{
${ }^{17}$ Garcia and Lovink, "The ABC of Tactical Media," Sarai Reader 2001: The Public Domain, ed. Jeebesh Bagchi, Monica Narula, Ravi Sundaram et all (Delhi: Center for Study of Developing Societies, 2001), pp. 91

${ }^{18}$ Sarai Reader 2001: The Public Domain, pp. 90.
} 


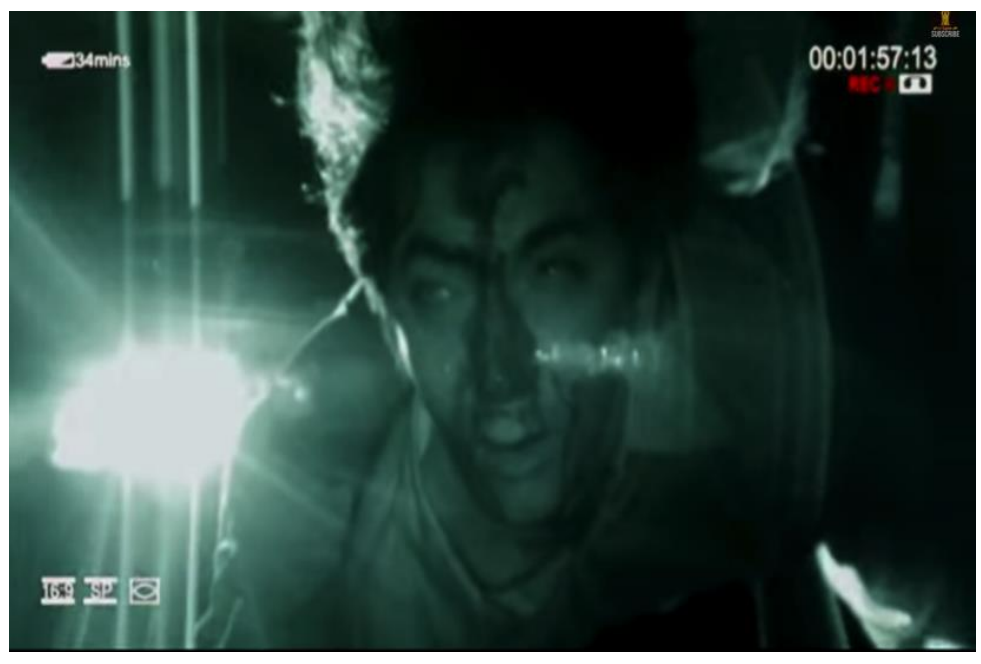

33.

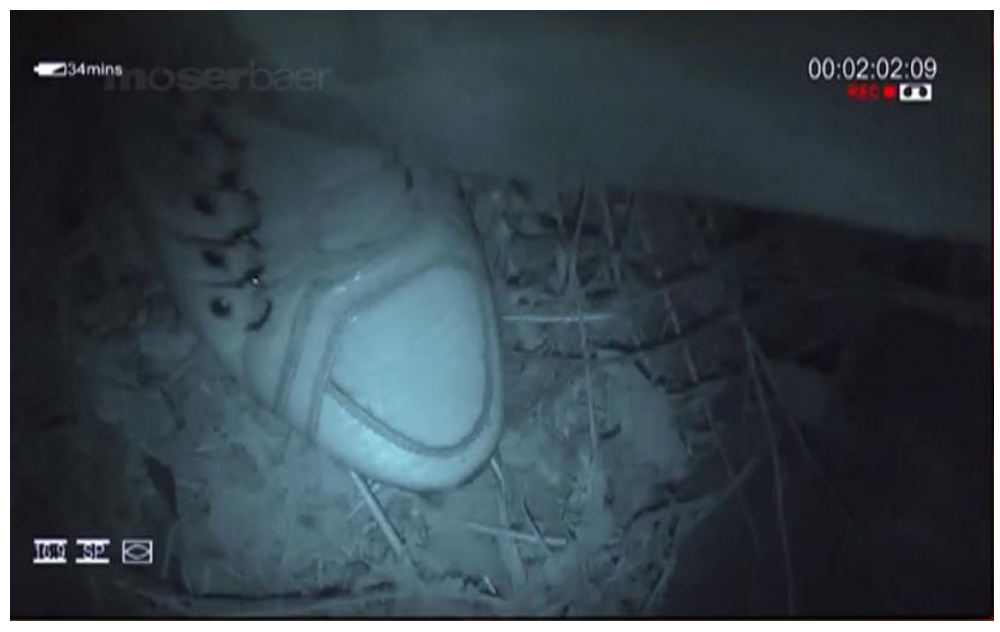

34.

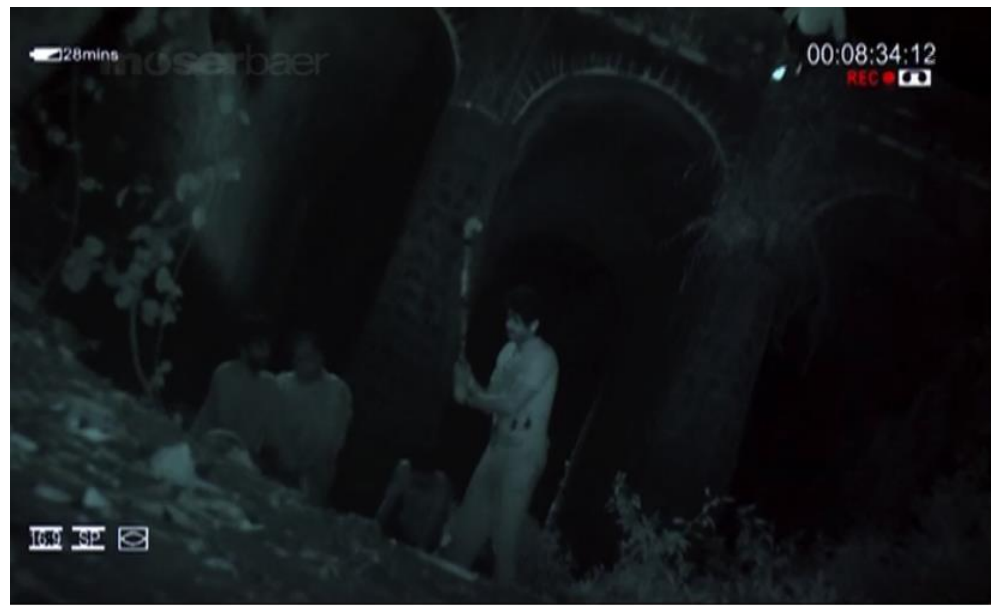

35.

As we observe the scene with shock, fear and sadness, we are also simultaneously moved by the camera along its own path of attention as it pulls us away from the characters with its slightly out of focus lens, its use of night vision, the sound of the lens 
deliriously zooming in and out, its scratched surface and, most importantly, the slight flicker of the screen as it witnesses and records the gruesome killings in a way that almost seems like a quiver with the camera drawing attention to its own materiality (Image 36). These set of movements - of both the human bodies in the scene and that of the camera are physically, and perceptually, disorienting. Banerjee's framing and camera movement place us too close to the characters for us not to be intimately involved, yet this still refuses us an anchor.

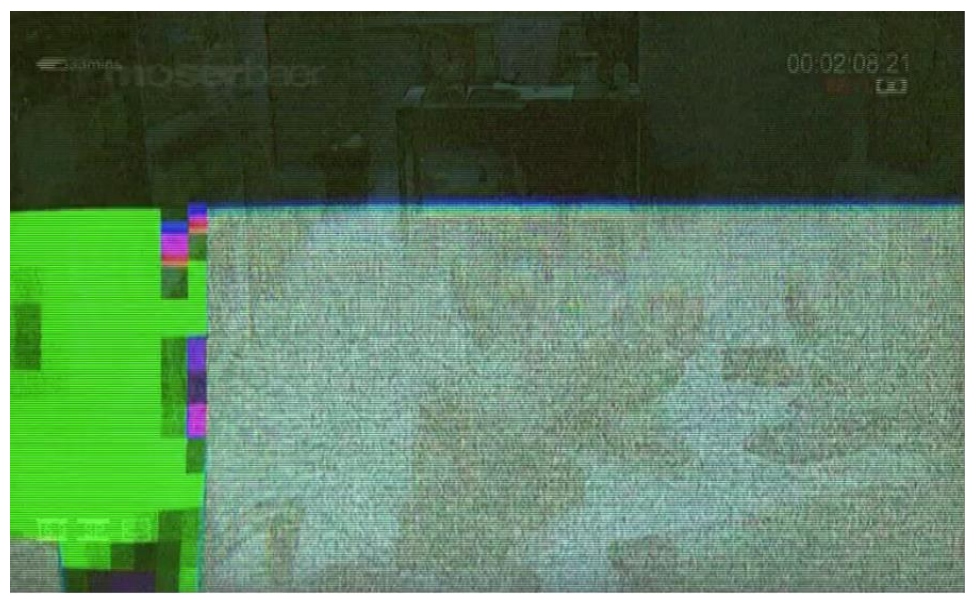

36.

Extreme close ups of Shruti's brother and his aide, along with Shruti's incessant screaming, draw us towards the scene. However, at the same time, the camera through its own very visible movements explicitly draws our attention towards its own body making its own presence felt, and pulling us away from the characters. We are moved emotionally and physically in two directions at once: towards the subjects of the camera, and the camera itself. In this sequence, as throughout the film, we are involved and immersed in the space and time of the events of the story, but without a single body with whom to align ourselves unequivocally.

The use of such a haptic style also allows Banerjee to create a meta-critical space to engage with the forms of spectatorship posited by the new media ecologies and marked by new arrangements of value and sensation. Significantly, Banerjee reminds us that 'new' Bombay cinema is part of this ecology by presenting the movie in three parts, and thereby enacting the production of new forms of cinematic commodity, consumed in fragments. Love Sex Aur Dhoka begins with an advertisement foregrounding the digitial 
camcorder as its prime attraction and inviting the viewers to watch the 'miracle' in the world of cinema - 'REALITY CINEMA!' It goes on to promise the spectators the thrill of watching sensational 'REAL' stories, three at the price of one, compiled from the footage taken from 'all the cameras in the world - spy camera, security camera, phone camera, home camera and secret camera.' As the sequence cuts to the first story, 'Super hit Love' with its manifold surveillance cameras, and hidden cameras Love Sex Aur Dhoka enacts the kind of voyeurism to which these stories appeal. ${ }^{19}$ The film constantly accentuates the nonpublic and nonprofessional status of the recordings - the shaky images, discordant lightning effects, poor camera placement, and random cuts - visually marking the texts as private. Even in its adoption of the digital, I would argue that rather than deeming digital as a 'radical' break, Love Sex Aur Dhoka in fact enacts a critique of such a technologically determinist understanding of the digital by an intensification ad absurdum of reality effects that have unsettling consequences for the characters as well as for us, the spectators.

Talking about the different types of cameras used for Love Sex Aur Dhoka and their setting, Barnejee and his cinematographer Nikos point out that at times the camera was strapped to the body of the actors, and in instances when it couldn't be, the choreographer had to move with the actor holding the camera as if in a dance 'so that it captures his movements so well that it convinces us that it is actually strapped on his chest' ${ }^{20}$ This parallel movement of character and camera is not a simple instance of an endeavour to create a duplication of reality, but instead it points to the material and tactile relation between the filming apparatus and the human body in the contemporary moment we, and the film, inhabit. In an interview in response to the question of the film being a 'digital film,' Banerjee points out that what the film is explicating is the 'current way of seeing a moving image to which we have been sensitized by various media forms ... over the last two decades [...].' I would argue that the film is drawing attention to these new embodied structures and patterns in a contemporary moment marked by the visceral presence of

\footnotetext{
${ }^{19}$ In her essay on Love Sex Aur Dhoka, Tanvir also suggests "the argument that the film makes is that digital technology has access to spaces that are devoid of the romance of 'fiction' and are in fact inhabited by a pervading violence. However, it simultaneously also spotlights the technology itself as the medium that engenders this violence, makes it manifest, visible, documented and ultimately erasable" (1).

${ }^{20}$ 2010, Website no more available. Accessed in May 2011.
} 
technology and immersion in an ubiquitous media culture. Exploring cinema's tactility, Jennifer Barker suggests 'opens up the possibility of cinema as an intimate experience and of our relationship with cinema as a close connection, rather than as a distant experience of observation, which the notion of cinema as a purely visual medium presumes'. ${ }^{21}$ In Love Sex Aur Dhoka, too, meaning and significance are articulated through a visceral engagement that occurs between the film's and the viewer's bodies.

In conclusion, I would say that what makes the film important, both in terms of the trajectory of Banerjee as a filmmaker and its significance within the contemporary public culture, is its ability to extend the terms of discussion of the contemporary sensorium and indicate both how liberating and oppressive this is. In this sense, the film is indicative of a potent moment in the post Bollywood history of Bombay cinema where such technological cultures are not simply understood as arbitrary signifiers of a secular, modernizing nation-state.

\footnotetext{
${ }^{21}$ Jennifer Barker, The Tactile Eye: Touch and the Cinematic Experience (Berkeley: University of
} California Press, 2009), pp. 2. 